\title{
Mosapride combined with probiotics on gastrointestinal function and growth in premature infants
}

\author{
AI-MEI ZHANG, ZHI-QUN SUN and LI-MING ZHANG \\ Department of Pediatrics, Weifang People's Hospital, Weifang, Shandong 261041, P.R. China
}

Received November 8, 2016; Accepted December 23, 2016

DOI: $10.3892 /$ etm.2017.4340

\begin{abstract}
The aim of this study was to investigate the effects of mosapride combined with probiotics on gastrointestinal function and growth and development in premature infants. A total of 240 premature infants treated at Weifang People's Hospital between June 2012 and May 2015 who matched our criteria were randomly divided into three groups of 80 cases each. Group A received routine treatment, group B received routine treatment combined with live B. subtilis and E. faecium granules with multivitamins (Medilac-Vita), and group $\mathrm{C}$ received routine treatment and Saccharomyces boulardii sachets (Bioflor). Mosapride was administered to patients in groups $\mathrm{B}$ and $\mathrm{C}$ to promote intestinal peristalsis. Gastrin and bilirubin levels, as well as jaundice fade time, were recorded. Growth and development condition (i.e., head circumference and weight), duration and incidence of feeding intolerance (FI), as well as other symptoms were also analyzed. By day 14, gastrin concentrations in groups $\mathrm{B}$ and $\mathrm{C}$ were significantly higher than those in group A $(\mathrm{P}<0.05)$. Serum bilirubin levels in groups $\mathrm{B}$ and $\mathrm{C}$ showed a progressive decline from day 7 to day 14 , and jaundice duration in group A was significantly longer $(\mathrm{P}<0.05)$. Furthermore, at 2 weeks, the average weight growth rate and head circumference were significantly greater in groups $\mathrm{B}$ and $\mathrm{C}$, weight loss recovery time was shorter, and EUGR incidence was lower $(\mathrm{P}<0.05)$. The incidence rate of gastric retention and FI were lower in groups $\mathrm{B}$ and $\mathrm{C}$ than group A $(\mathrm{P}<0.05)$, and neonatal hyperbilirubinemia, parenteral nutrition-associated cholestasis, necrotizing enterocolitis, and neonatal sepsis incidence was significantly lower in groups $\mathrm{B}$ and $\mathrm{C}(\mathrm{P}<0.05)$. Mosapride combined with probiotics can effectively reduce FI incidence in premature infants, shorten enteral feeding time, promote the absorption of required nutrients, and promote the development and recovery of early physiological weight loss in preterm infants.
\end{abstract}

Correspondence to: Dr Zhi-Qun Sun, Department of Pediatrics, Weifang People's Hospital, 151 Guangwen Road, Weifang, Shandong 261041, P.R. China

E-mail: qtrojz3355@163.com

Key words: premature infant, mosapride, probiotics, gastrointestinal function, growth and development

\section{Introduction}

In order to improve the survival rate of premature infants, reasonable feeding methods and nutritional supply are the focus of pediatrician. Due to the small gestational age, gastrointestinal motility is poor in premature infants, and a variety of digestive enzymes have a low secretion, low content and poor activity. Therefore, premature infants when feeding often have abdominal distension, vomiting, gastric retention and other phenomena, and their nutritional status is worse than that of healthy children, which affects growth and development. Although long-term use of parenteral nutrition can provide adequate and effective nutrition, it also easily leads to parenteral nutrition-associated cholestasis (PNAC) $(1,2)$. Therefore, during the period of hospitalization in premature infants, the challenge for pediatricians is how to solve issues, such as low digestion and absorption capacity and poor gastrointestinal motility.

Probiotics can improve the formation and colonization of normal flora in the gastrointestinal tract of preterm infants, change the $\mathrm{pH}$ value to make the beneficial normal flora dominant, and supplement the early aseptic environment of the gastrointestinal tract (3). Thus, the secretion of digestive enzymes and lactic acid bacteria is improved, and the decomposition and absorption of proteins and carbonic acid compounds are promoted. In addition, gastrointestinal motility drugs can promote gastrointestinal peristalsis, enhance gastrointestinal motility, promote the uptake and utilization of nutrients, and reduce feeding intolerance (FI) (4).

Therefore, this study compared the effects of mosapride combined with live combined B. subtilis and E. faecium granules or Saccharomyces boulardii sachets on gastrointestinal function and growth and development of premature infants, thus providing a scientific and reliable theoretical basis for reducing gastrointestinal complications and improving the quality of life and nutritional status of preterm infants.

\section{Patients and methods}

Case inclusion criteria. The following criteria were employed for selecting appropriate cases for this study: i) Premature infants: Gestational age $<37$ weeks; ii) birth weight $<2,500 \mathrm{~g}$; iii) normal gestational age infant; iv) immediately 
transferred to NICU for treatment within $24 \mathrm{~h}$ after birth; v) hospitalization time $\geq 2$ weeks, during which premature infants were cured or improved; and vi) treatment effect and suckling ability was good during hospitalization, and weight increased by 10-30 g/day without fatal complications [respiratory failure or acute respiratory distress syndrome (ARDS)]. This study was approved by the Ethics Committee of Weifang People's Hospital (Weifang, China). Signed written informed consent was obtained from the parents of all infants before the study.

Case exclusion criteria. The following criteria were employed to exclude cases from this study: i) Premature infants who had allergy to probiotics; ii) neonatal ARDS, apnea, swallowing syndrome, digestive tract malformation and hemorrhage, congenital heart diseases, intracranial hemorrhage, and inherited metabolic diseases.

General information. A total of 240 premature infants (149 males, 91 females) who were treated at the Weifang People's Hospital between June 2012 and May 2015, and who were in compliance with the aforementioned inclusion criteria, were randomly divided into three groups of 80 each. Group A received routine treatment, group B received routine treatment with live $B$. subtilis and E. faecium granules with multivitamins (Medilac-Vita, $1 \mathrm{~g} /$ bottle, 0.33 bottle each time, bid), and group $\mathrm{C}$ received routine treatment and Saccharomyces boulardii sachets (Bioflor, $0.25 \mathrm{~g} / \mathrm{bag}$, half bag each time, qd). Mosapride ( $5 \mathrm{mg} /$ tablet, $0.5 \mathrm{mg}$ each time, tid) was administered to patients in groups $\mathrm{B}$ and $\mathrm{C}$ to promote intestinal peristalsis.

Routine treatment. After admission, all three groups were administered routine treatment consisting of premature infant care and warmth retention. In accordance with the Guidelines for the Management of Preterm Infants and Chinese Guidelines for Newborn Nutrition Support in Neonates of 2006 and Recommendations for Feeding Preterm/Low Birth Weight Infants of 2010 formulated by the Chinese Medical Association, preterm infants in this study were treated with nutritional support. Adjustments to feeding, including milk and trace element nutritional requirements, were carried out based on suckling conditions and weight growth of each premature infant. In addition, if the premature infants could not intestinally tolerate the administered treatment, parenteral nutrition support was required. Glucose, milk fat, proteins, other nutrients, and liquids were provided according to the weight and need of each premature infant.

\section{Monitoring index}

Determination of gastrin and bilirubin levels. On days 1, 3, 7 and 14 after birth, fasting serum gastrin concentrations and bilirubin levels [including total bilirubin (TBIL) and indirect bilirubin (IBIL) levels] were determined by radioimmunoassay in all three groups. Jaundice fading time was also recorded.

Determination of growth and development. Body weight was measured at the same time each day, accurate to within $10 \mathrm{~g}$. Weight at discharge and minimum weight values were recorded. Days of recovery from physiological weight loss

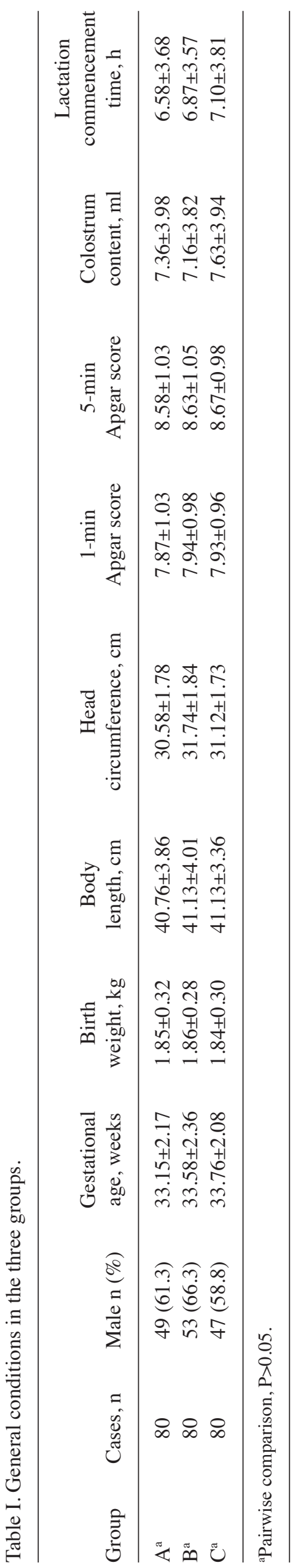


Table II. Comparison of serum gastrin concentrations.

Serum gastrin concentration, $\mathrm{pg} / \mathrm{ml}$

\begin{tabular}{lccccc}
\cline { 3 - 5 } Group & Cases, $\mathrm{n}$ & Day 1 & Day 3 & Day 7 & Day 14 \\
\hline A & 80 & $38.43 \pm 8.21$ & $39.23 \pm 8.56$ & $44.12 \pm 9.23$ & $46.82 \pm 11.56$ \\
B & 80 & $39.16 \pm 8.57$ & $39.87 \pm 9.12$ & $45.56 \pm 10.56$ & $53.54 \pm 15.78^{\mathrm{a}}$ \\
C & 80 & $39.24 \pm 9.01$ & $40.12 \pm 9.25$ & $45.87 \pm 9.87$ & $54.67 \pm 15.89^{\mathrm{a}}$ \\
$F$ & 2.64 & 3.12 & 6.87 & 11.24
\end{tabular}

${ }^{\mathrm{a} C o m p a r e d ~ w i t h ~ g r o u p ~ A, ~} \mathrm{P}<0.05$.

Table III. Comparison of jaundice and serum total bilirubin levels $(\mu \mathrm{mol} / \mathrm{l})$ between the three groups.

\begin{tabular}{lccccc}
\hline Group & Cases, $\mathrm{n}$ & Pre-treatment & Day 7 & Day 14 & Jaundice fade time, day \\
\hline A & 80 & $226.78 \pm 21.54$ & $154.56 \pm 32.18$ & $124.18 \pm 28.56$ & $14.25 \pm 4.56$ \\
B & 80 & $226.15 \pm 21.78$ & $121.23 \pm 21.56^{\mathrm{a}}$ & $56.87 \pm 23.71^{\mathrm{a}}$ & $10.56 \pm 3.51^{\mathrm{a}}$ \\
C & 80 & $225.67 \pm 22.15$ & $132.54 \pm 25.67^{\mathrm{a}}$ & $78.18 \pm 21.58^{\mathrm{a}, \mathrm{b}}$ & $12.74 \pm 4.78^{\mathrm{a}}$ \\
$F$ & & & 22.87 & 14.32 & 15.81 \\
\hline
\end{tabular}

${ }^{\mathrm{a} C}$ Compared with group $\mathrm{A}, \mathrm{P}<0.05 ;{ }^{\mathrm{b}}$ compared with group $\mathrm{B}, \mathrm{P}<0.05$.

to birth weight were calculated. The occurrence of EUGR at discharge was recorded. In addition, head circumference was measured every day.

Nutritional intake. Increases in daily milk intake, and milk intake on days 7 and 14 were recorded. Time to reach full enteral feeding and length of stay were also recorded.

Prevalence of complications. The incidence of FI in the three groups was observed and recorded. The occurrence of gastrointestinal symptoms (i.e., vomiting, poor bowel movements, abdominal distension and gastric retention) was analyzed. We also observed the frequency of defecation and meconium discharge and drainage times. The occurrences of neonatal sepsis, PNAC, necrotizing enterocolitis (NEC), electrolyte disorders, abnormal blood glucose levels, and neonatal hyperbilirubinemia (NHB) were recorded.

Statistical analysis. Statistical analysis was performed using SPSS 17.0 software (SPSS, Inc., Chicago, IL, USA). Enumeration data were expressed as percentage (\%), and the $\chi^{2}$ test was used for comparison between groups. Measurement data were expressed as mean \pm standard deviation, and t-tests were used for comparisons. $\mathrm{P}<0.05$ was considered to indicate a statistically significant difference.

\section{Results}

Comparison of general conditions in three groups. The general conditions of patients in the three groups were compared, including gender ratio, gestational age, birth weight, body length, head circumference, 1-min Apgar score, 5-min Apgar score, colostrum content, and time of lactation commencement. The differences were not statistically significant $(\mathrm{P}>0.05$; Table I).

Comparison of serum gastrin concentration. There were no significant differences in fasting serum gastrin concentration on days 1, 3 and 7 in the three groups $(\mathrm{P}>0.05)$. However, on day 14 , gastrin concentrations in groups $\mathrm{B}$ and $\mathrm{C}$ were significantly higher than those in group $\mathrm{A}(\mathrm{P}<0.05)$. No significant difference was observed between groups $\mathrm{B}$ and $\mathrm{C}(\mathrm{P}>0.05$; Table II).

Comparison of serum bilirubin levels and jaundice fade time. Serum levels of TBIL in the three groups were measured on days 1, 7 and 14 after birth. Serum bilirubin levels in groups $\mathrm{B}$ and $\mathrm{C}$ showed a progressive decline from day 7 to day 14. The decrease in TBIL levels of group B was significantly larger than that of group $\mathrm{C}(\mathrm{P}<0.05)$. Jaundice fading time in group A was significantly longer and serum bilirubin levels were higher on days 7 and 14 compared to the other two groups. Pairwise comparisons showed that there were significant differences in TBIL levels $(\mathrm{P}<0.05$; Table III).

Comparison of growth and development in the three groups. The average weight growth rate, recovery time from physiological weight loss to birth weight, head circumference, and incidence rate of EUGR within 2 weeks were compared in the three groups. The average weight growth rate and head circumference within 2 weeks in groups B and C were significantly larger than those in group A $(\mathrm{P}<0.05)$. Furthermore, recovery time was shorter and the incidence of EUGR was significantly lower in groups B and C compared to group A $(\mathrm{P}<0.05)$. No significant differences were observed between groups $\mathrm{B}$ and $\mathrm{C}(\mathrm{P}>0.05$; Table IV). 
Table IV. Comparison of growth and development in the three groups.

\begin{tabular}{|c|c|c|c|c|c|}
\hline Group & Cases, $\mathrm{n}$ & $\begin{array}{l}\text { Average weight } \\
\text { growth rate, g/day }\end{array}$ & $\begin{array}{l}\text { Time of recovery } \\
\text { to birth weight, day }\end{array}$ & $\begin{array}{l}\text { Head circumference } \\
\text { within } 2 \text { weeks, cm }\end{array}$ & $\begin{array}{l}\text { Incidence rate } \\
\text { of EUGR n }(\%)\end{array}$ \\
\hline A & 80 & $16.23 \pm 3.18$ & $12.10 \pm 3.89$ & $31.78 \pm 1.56$ & $43(53.8)$ \\
\hline B & 80 & $17.81 \pm 3.87^{\mathrm{a}}$ & $10.21 \pm 3.56^{\mathrm{a}}$ & $32.45 \pm 1.41$ & $28(35.0)^{\mathrm{a}}$ \\
\hline $\mathrm{C}$ & 80 & $18.25 \pm 3.98^{\mathrm{a}}$ & $11.34 \pm 3.23^{\mathrm{a}}$ & $32.56 \pm 1.24$ & $30(37.5)^{\mathrm{a}}$ \\
\hline$F$ & & 18.23 & 6.28 & 8.54 & 6.80 \\
\hline
\end{tabular}

${ }^{a}$ Compared with group A, $\mathrm{P}<0.05$.

Table V. Comparison of feeding intolerance in the three preterm infant groups.

\begin{tabular}{|c|c|c|c|c|c|}
\hline Group & Cases (n) & $\begin{array}{l}\text { Duration of abdominal } \\
\text { distension, day }\end{array}$ & $\begin{array}{c}\text { Duration of } \\
\text { vomiting, day }\end{array}$ & $\begin{array}{l}\text { Tube indwelling } \\
\text { time, day }\end{array}$ & $\begin{array}{c}\text { Incidence rate } \\
\text { of FI n }(\%)\end{array}$ \\
\hline A & 80 & $7.12 \pm 1.54^{b, c}$ & $6.56 \pm 1.21^{\mathrm{b}, \mathrm{c}}$ & $5.34 \pm 2.51^{b, c}$ & $28(35.0)^{b, c}$ \\
\hline B & 80 & $4.87 \pm 1.43^{\mathrm{a}, \mathrm{c}}$ & $4.51 \pm 1.23^{\mathrm{a}, \mathrm{c}}$ & $3.56 \pm 2.12^{\mathrm{a}, \mathrm{c}}$ & $17(21.3)^{\mathrm{a}, \mathrm{c}}$ \\
\hline $\mathrm{C}$ & 80 & $4.51 \pm 1.41^{\mathrm{a}, \mathrm{b}}$ & $4.13 \pm 1.36^{\mathrm{a}, \mathrm{b}}$ & $3.42 \pm 2.16^{\mathrm{a}, \mathrm{b}}$ & $15(18.8)^{\mathrm{a}, \mathrm{b}}$ \\
\hline$F$ & & 18.23 & 6.28 & 8.54 & 6.54 \\
\hline
\end{tabular}

${ }^{\mathrm{a} C}$ Compared with group A, $\mathrm{p}<0.05$; ${ }^{\mathrm{b}}$ compared with group $\mathrm{B}, \mathrm{p}<0.05$; ${ }^{\mathrm{c}}$ compared with group $\mathrm{C}, \mathrm{p}<0.05$. FI, feeding intolerance.

Table VI. Comparison of gastrointestinal motility in the three groups.

\begin{tabular}{|c|c|c|c|c|c|}
\hline Group & Cases, $\mathrm{n}$ & $\begin{array}{c}\text { First } \\
\text { defecation time, } \mathrm{h}\end{array}$ & $\begin{array}{c}\text { Average stool } \\
\text { frequency, times/day }\end{array}$ & $\begin{array}{c}\text { Meconium } \\
\text { drainage time, day }\end{array}$ & $\begin{array}{c}\text { Enteral } \\
\text { nutrition time, } \mathrm{h}\end{array}$ \\
\hline A & 80 & $23.87 \pm 15.46^{\mathrm{b}, \mathrm{c}}$ & $3.24 \pm 0.68^{\mathrm{b}, \mathrm{c}}$ & $119.78 \pm 29.78^{\mathrm{b}, \mathrm{c}}$ & $12.59 \pm 2.31^{\mathrm{b}, \mathrm{c}}$ \\
\hline B & 80 & $18.56 \pm 14.87^{\mathrm{a}, \mathrm{c}}$ & $3.97 \pm 0.59^{\mathrm{a}, \mathrm{c}}$ & $98.75 \pm 33.68^{\mathrm{a}, \mathrm{c}}$ & $10.23 \pm 2.12^{\mathrm{a}, \mathrm{c}}$ \\
\hline $\mathrm{C}$ & 80 & $17.52 \pm 14.12^{\mathrm{a}, \mathrm{b}}$ & $3.92 \pm 0.64^{\mathrm{a}, \mathrm{b}}$ & $94.52 \pm 29.53^{\mathrm{a}, \mathrm{b}}$ & $9.85 \pm 1.98^{\mathrm{a}, \mathrm{b}}$ \\
\hline$F$ & & 5.48 & 12.78 & 11.16 & 6.89 \\
\hline
\end{tabular}

${ }^{\mathrm{a} C}$ Compared with group A, $\mathrm{p}<0.05$; ${ }^{\mathrm{b}}$ compared with group $\mathrm{B}, \mathrm{p}<0.05$; $^{\mathrm{c}}$ compared with group $\mathrm{C}, \mathrm{p}<0.05$. FI, feeding intolerance.

Comparison of gastrointestinal discomfort in the three groups of preterm infants. The duration of abdominal distension, vomiting, and other symptoms, as well as the duration of the indwelling gastric tube, were shorter, and incidence rates of gastric retention and FI were lower, in groups $\mathrm{B}$ and $\mathrm{C}$ compared with group $\mathrm{A}(\mathrm{P}<0.05)$. A comparison between groups $\mathrm{B}$ and $\mathrm{C}$ showed that there were no significant differences in the incidence rate of FI and the duration of symptoms such as abdominal distension and vomiting ( $\mathrm{P}>0.05$; Table $\mathrm{V})$.

Comparison of gastrointestinal motility. During hospitalization, the first defecation time in the three groups were $23.87 \pm 15.46,18.56 \pm 14.87$ and $17.52 \pm 14.12 \mathrm{~h}$, respectively. First defecation time and meconium drainage times were both longer, and the average stool frequency was decreased, in group A compared to groups B and C $(\mathrm{P}<0.05$; Table VI).
Comparison of related nutritional complication incidence rates. Occurrence of neonatal sepsis, PNAC, NEC, electrolyte disorders, abnormal blood glucose levels, and NHB were compared in the three groups. There were no significant differences in the incidence rates of electrolyte disorders and abnormal glucose levels in the three groups $(\mathrm{P}>0.05)$. The incidence rates of NHB, PNAC, NEC, and neonatal sepsis in groups $\mathrm{B}$ and $\mathrm{C}$ were lower than those in group $\mathrm{A}$, and the difference was statistically significant $(\mathrm{P}>0.05)$. The incidence rate of neonatal sepsis in group $\mathrm{C}$ was statistically lower than that in group B ( $\mathrm{P}>0.05$; Table VII and Fig. 1).

\section{Discussion}

The development of medical technology and popularization of perinatal medicine has led to an increase in the survival rate of premature infants (5). Enteral nutritional support in premature infants promotes the gradual maturation of the 
Table VII. Related nutritional complications in preterm infants.

\begin{tabular}{lccccccc}
\hline Group & Cases (n) & $\begin{array}{c}\text { Septicemia } \\
\text { n (\%) }\end{array}$ & PNAC n (\%) & NEC n (\%) & $\begin{array}{c}\text { Electrolyte } \\
\text { disorder n (\%) }\end{array}$ & $\begin{array}{c}\text { Abnormal blood } \\
\text { glucose levels (\%) }\end{array}$ & NHB n (\%) \\
\hline A & 80 & $14(17.5)$ & $11(13.75)$ & $12(15)$ & $8(10)$ & $8(10)$ & $25(31.25)$ \\
B & 80 & $5(6.25)$ & $2(2.5)$ & $3(3.75)$ & $7(8.75)$ & $9(11.25)$ & $6(7.5)$ \\
C & 80 & $1(1.25)$ & $3(3.75)$ & $4(5)$ & $8(10)$ & $8(10)$ & $14(17.5)$ \\
$F$ & & 14.51 & 9.78 & 8.34 & 0.1 & 0.09 & 14.93 \\
\hline
\end{tabular}

PNAC, parenteral nutrition-associated cholestasis; NEC, necrotizing enterocolitis; NHB, neonatal hyperbilirubinemia.

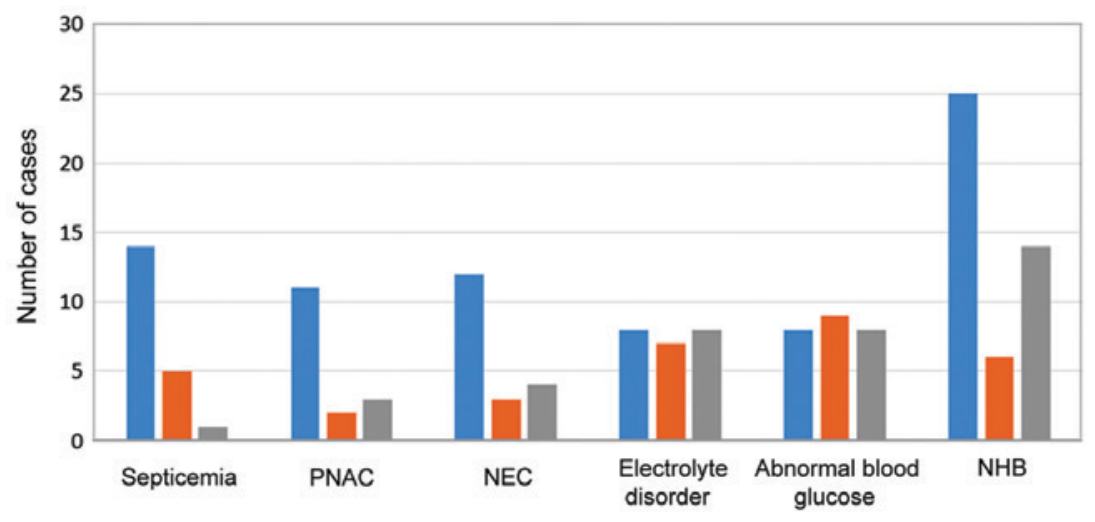

Figure 1. Related nutritional complications in the three groups. PNAC, parenteral nutrition-associated cholestasis; NEC, necrotizing enterocolitis; NHB, neonatal hyperbilirubinemia.

intestinal mucosa, establishment of the functions of digestion and absorption, and reduces bacterial translocation, changes in intestinal osmotic pressure, and endogenous gut infections (6). However, the digestive system and the neuroendocrine regulation of the gastrointestinal tract in premature infants are not mature, which leads to low gastrointestinal endocrine hormone levels, weak gastrointestinal motility, and uncoordinated movements. Due to stress responses caused by various factors after birth, the normal intestinal flora and the Lactobacillus bacteria group (7) have not been fully established. As such, enteral feeding in preterm infants is prone to symptoms of FI (8). Previous findings have shown that depending on the $\mathrm{pH}$, osmotic pressure, and the special physiology of the bacteria in the intestinal tracts of preterm infants, the microecology can promote the formation and colonization of beneficial intestinal flora or normal flora in the host, maintain intestinal microecological balance, improve $\mathrm{T} / \mathrm{B}$ cellular immunity and humoral immunity, increase the ability of the monocyte-macrophage system, and improve disease prevention, defense, and treatment $(9,10)$. Mosapride is a new type of drug designed to promote gastrointestinal motility and increase the release of acetylcholine by stimulating 5-HT receptors in intestinal cholinergic interneurons and intercostal neurons. Thus, mosapride enhances the movement of the upper gastrointestinal tract such as the stomach and the duodenum, promotes gastric emptying, reduces gastroesophageal reflux (11), and improves gastrointestinal discomfort caused by functional dyspepsia and irritable bowel syndrome (12).
The results of this study showed that mosapride combined with probiotics promoted the secretion of serum gastrin and shortened the duration of hyperbilirubinemia in preterm infants. On days 7 and 14, gastrin levels were significantly higher and TBIL levels were significantly lower in mosapride-treated infants than infants receiving conventional treatment. In addition, bilirubin levels in premature infants treated with Medilac-Vita were much lower than those in infants treated with Bioflor. Gastrin is an important gastrointestinal hormone that promotes the maturation of the intestinal mucosa and digestive function, and indirectly reflects the maturation and development of the intestinal tract (13). Probiotics combined with mosapride increased serum gastrin secretion, promoted the excretion of IBIL, and reduced the development of neonatal bilirubin. Live binary Bacillus subtilis in Medilac-Vita may promote liver enzyme activity and increase the combination of IBIL and glucose acid to promote bilirubin excretion (14).

Administration of mosapride combined with probiotics in premature infants also reduced the incidence and duration of vomiting, abdominal distension, poor bowel movements, and other FI symptoms, promoted the secretion of gastrointestinal hormones and the absorption and uptake of nutrients in the early stage, and resulted in the acceleration of weight and head circumference growth (15) in order that the incidence of EUGR was significantly reduced. We found that the incidence of FI in group A was $35.0 \%$ (28/80), and the incidence in groups B and C were $21.3 \%$ (17/80) and 18.8\% (15/80), respectively, which were significantly lower than in group $\mathrm{A}(\mathrm{P}<0.05)$. Moreover, the duration of FI symptoms was gradually short- 
ened in the three groups, with the durations in groups B and C being significantly shorter compared to group A $(\mathrm{P}<0.05)$. These results suggest that mosapride combined with probiotics can promote intestinal peristalsis and maturation, reduce infection and gastrointestinal dysfunction, and improve FI and other symptoms. In this study, the average weight growth rate and head circumference within 2 weeks in groups $B$ and $C$ were both significantly larger than that in group $\mathrm{A}(\mathrm{P}<0.05)$. In addition, compared with group $\mathrm{A}$, body weight recovery time was shorter and the incidence of EUGR was significantly lower in groups $\mathrm{B}$ and $\mathrm{C}(\mathrm{P}<0.05)$. This result may be due to the fact that probiotics can, not only improve gastrointestinal function, but also synthesize a variety of important vitamins, folic acid, and other nutrients for the body to synthesize amino acids, maintain intestinal $\mathrm{pH}$, and reduce the incidence of neonatal NEC (16).

Previous findings have indicated that defecation delay or changes in stool frequency often occur before the weakening of upper gastrointestinal motility and reduction of gastric emptying, which are positively correlated with abnormal colonic motility. Difficult defecation increases the occurrence and severity of FI, prolongs the length of stay, and increases the incidence of NHB (17). The current results showed that the application of the combined medication could clearly improve difficult defecation, promote meconium exclusion, and increase stool frequency. First defecation time and meconium drainage time were both longer in group $\mathrm{A}$ than those in groups $\mathrm{B}$ and $\mathrm{C}(\mathrm{P}<0.05)$. The incidence rates of $\mathrm{NHB}, \mathrm{PNAC}$, NEC, and neonatal sepsis in groups $B$ and $C$ were lower than that in group A $(\mathrm{P}>0.05)$. Moreover, the incidence rate of neonatal sepsis in group $C$ was statistically lower than that in group $\mathrm{B}(\mathrm{P}>0.05)$. Thus, probiotics can inhibit the excessive propagation of pathogenic bacteria, enhance the barrier function of the intestinal mucosa (18), and reduce intestinal flora imbalance, thereby reducing blood-borne infections and incidence of neonatal septicemia $(19,20)$. No adverse reactions were found in this study, suggesting that the probiotic preparation was safe for preterm infants.

In conclusion, mosapride combined with two kinds of probiotics effectively reduced the incidence of FI, prevented gastrointestinal dysfunction, reduced difficulty in defecation, shortened meconium drainage time, promoted the development and maturation of intestinal mucosa, improved the intestinal environment and the colonization of normal flora, increased the secretion of gastrointestinal hormones, shorten enteral feeding time, promoted the absorption of required nutrients, and promoted the recovery of body weight and head circumference growth in premature infants.

\section{References}

1. Steinbach M, Clark RH, Kelleher AS, Flores C, White R, Chace DH and Spitzer AR; Pediatrix Amino-Acid Study Group: Demographic and nutritional factors associated with prolonged cholestatic jaundice in the premature infant. J Perinatol 28 $129-135,2008$
2. Hsieh MH, Pai W, Tseng HI, Yang SN, Lu CC and Chen HL: Parenteral nutrition-associated cholestasis in premature babies: Risk factors and predictors. Pediatr Neonatol 50: 202-207, 2009 .

3. Hao WL and Lee YK: Microflora of the gastrointestinal tract: A review. Methods Mol Biol 268: 491-502, 2004.

4. Lee SJ, Cho SJ and Park EA: Effects of probiotics on enteric flora and feeding tolerance in preterm infants. Neonatology 91: 174-179, 2007.

5. Serenius F, Källén K, Blennow M, Ewald U, Fellman V, Holmström G, Lindberg E, Lundqvist P, Maršál K, Norman M, et al; EXPRESS Group: Neurodevelopmental outcome in extremely preterm infants at 2.5 years after active perinatal care in Sweden. JAMA 309: 1810-1820, 2013.

6. Mehta NM: Approach to enteral feeding in the PICU. Nutr Clin Pract 24: 377-387, 2009.

7. Schwiertz A, Gruhl B, Löbnitz M, Michel P, Radke M and Blaut M: Development of the intestinal bacterial composition in hospitalized preterm infants in comparison with breast-fed, full-term infants. Pediatr Res 54: 393-399, 2003.

8. Ng E and Shah VS: Erythromycin for the prevention and treatment of feeding intolerance in preterm infants. Cochrane Database Syst Rev 16: CD001815, 2008.

9. Salminen S and Arvilommi H: Probiotics demonstrating efficacy in clinical settings. Clin Infect Dis 32: 1577-1578, 2001.

10. von Kiedrowski R, Huijghebaert S and Raedsch R: Mechanisms of cisapride affecting gallbladder motility. Dig Dis Sci 46: 939-944, 2001

11. Koshino K, Adachi K, Furuta K, Ohara S, Morita T, Nakata S, Tanimura T, Miki M and Kinoshita Y: Effects of mosapride on esophageal functions and gastroesophageal reflux. J Gastroenterol Hepatol 25: 1066-1071, 2010.

12. Hongo M, Harasawa S, Mine T, Sasaki I, Matsueda K, Kusano M, Hanyu N, Nakada K and Shibata C: Large-scale randomized clinical study on functional dyspepsia treatment with mosapride or teprenone: Japan Mosapride Mega-Study (JMMS). J Gastroenterol Hepatol 27: 62-68, 2012.

13. Yang CY, Lien R, Fu RH, Chu SM, Hsu JF, Lai JY, Minoo P and Chiang MC: Prognostic factors and concomitant anomalies in neonatal gastric perforation. J Pediatr Surg 50: 1278-1282, 2015.

14. Gewolb IH, Schwalbe RS, Taciak VL, Harrison TS and Panigrahi P: Stool microflora in extremely low birthweight infants. Arch Dis Child Fetal Neonatal Ed 80: F167-F173, 1999.

15. Keunen K, van Elburg RM, van Bel F and Benders MJ: Impact of nutrition on brain development and its neuroprotective implications following preterm birth. Pediatr Res 77: 148-155, 2015.

16. Robinson DT and Caplan MS: Linking fat intake, the intestinal microbiome, and necrotizing enterocolitis in premature infants. Pediatr Res 77: 121-126, 2015.

17. Jadcherla SR and Kliegman RM: Studies of feeding intolerance in very low birth weight infants: Definition and significance. Pediatrics 109: 516-517, 2002.

18. Rautava S: Potential uses of probiotics in the neonate. Semin Fetal Neonatal Med 12: 45-53, 2007.

19. Macpherson AJ, Hunziker L, McCoy K and Lamarre A: IgA responses in the intestinal mucosa against pathogenic and non-pathogenic microorganisms. Microbes Infect 3: 1021-1035, 2001.

20. Nair V and Soraisham AS: Probiotics and prebiotics: role in prevention of nosocomial sepsis in preterm infants. Int $\mathbf{J}$ Pediatr 2013: 874726, 2013. 